\title{
PHYSICAL AND CHEMICAL PROPERTIES OF SOME GREEK KAOLINS OF DIFFERENT ENVIRONMENTS OF ORIGIN
}

\author{
Tsolis-Katagas P. ${ }^{1}$ and Papoulis D. ${ }^{1}$ \\ ${ }^{1}$ Department of Earth Materials, School of Geology, University of Patras, 26500 Patras, \\ n.tsoli-kataga@upatras.gr, papoulis@upatras.gr
}

\begin{abstract}
Two widely different kaolin deposits were investigated in order to determine their physical and chemical properties and suggest their possible utilization. Kaolin deposits from Leucogia area, NE Greece, were formed in situ by weathering of gneissic rocks under a temperate climate; they consist largely of halloysite exhibiting different morphological forms, and stacks and plates of kaolinite in various proportions. The kaolin occurrences of Kos island are products of hydrothermally altered rhyolitic rocks of Pliocene age. The highly altered samples contain dickite and kaolinite.

Testing included particle size distribution, brightness and whiteness, measurement of CEC (cation exchange capacity) and some ceramic properties including Atterberg limits. The CEC values range between 3.8-8 meq/100 $\mathrm{g}$ and 0.8-2.2 meq/100 $\mathrm{g}$ for kaolin samples from Leucogia and Kos island respectively and reflect the differences in clay mineralogy and the characteristic kaolin mineral present. Platy halloysite enhances CEC in Leucogia kaolins while kaolinite-rich samples in Kos exhibit higher CEC values than dickite-rich samples. Atterberg limit tests reveal the Leucogia and Kos kaolins to be of low to medium plasticity and to be classified in the category of kaolinitic clays suitable for brick making. The Leucogia kaolin shows relatively higher brightness (47-60\%) and whiteness $(62-77 \%)$ than Kos kaolin (41-48\% and 61-66\% respectively). These properties are influenced by the type of kaolin mineral present, their relative proportions and the $\mathrm{Fe}_{2} \mathrm{O}_{3}$ content of the samples. The obtained values for brightness and whiteness from both areas are lower compared to the standard commercial kaolins for the paper and filler market. Brightness, however, can be improved by fine grinding and refinement. The physical, chemical and mineralogical properties of Leucogia and Kos kaolins indicate that they are of low grade type. However, kaolin processing from the crude state can optimize some of these highly commercial properties.
\end{abstract}

\section{INTRODUCTION}

Kaolins are important materials having major geological and industrial significance. The kaolin minerals kaolinite, halloysite, dickite and nacrite are essentially of similar chemical composition but they have important structural and stacking differences. The most common kaolin mineral is kaolinite $\left[\mathrm{Al}_{2} \mathrm{Si}_{2} \mathrm{O}_{5}(\mathrm{OH})_{4}\right]$. Several factors including the geological conditions of formation, the total mineralogical composition of the kaolin deposit, and the physical and chemical properties may affect the industrial application of this material. As mentioned by Murray \& Keller (1993) there are "Kaolins, Kaolins and Kaolins". Kaolin deposits can be of hydrothermal, residual or sedimentary origin. The first two are classified as primary and the third as secondary. The mode of formation of the kaolins depends on the mineralogy, chemistry and morphology of the kaolin minerals, which may affect their physical and chemical characteristics and their ultimate industrial applications (Murray 1991).

In the present work a systematic study has been carried out on the properties of two Greek kaolin deposits having a different geological origin and their possible applications in industry are suggested. 


\section{GEOLOGICAL SETTING AND SAMPLE LOCATION}

Two widely different kaolin deposits were studied a) from Leucogia area NE Greece and b) from Kos island, Aegean Sea. Figure 1 shows the locations of the different deposits.

\subsection{Leucogia kaolins}

The kaolin deposits of Leucogia area, are considered residual weathering products of coarsely crystalline and thinly bedded leucocratic amphibolite-facies gneisses and shist-gneisses (Fig. 2) (Michailidis \& Tsirambides 1986). They extend over an area of about $20 \mathrm{~km}^{2}$ and their thicknesses range from 1 to $50 \mathrm{~m}$ depending on the topographic relief. The kaolins consist mostly of kaolinite and halloysite in various proportions with an average total amount not exceeding $50 \%$ (Papoulis 2003). Mineral constituents vary in morphology (Fig. 3), while a gradual transition from fresh rock to kaolin is observed (Papoulis et al. 2004). Kaolinite predominates near the surface of the highly weathered gneisses, whereas deeper levels are progressively enriched in halloysite.

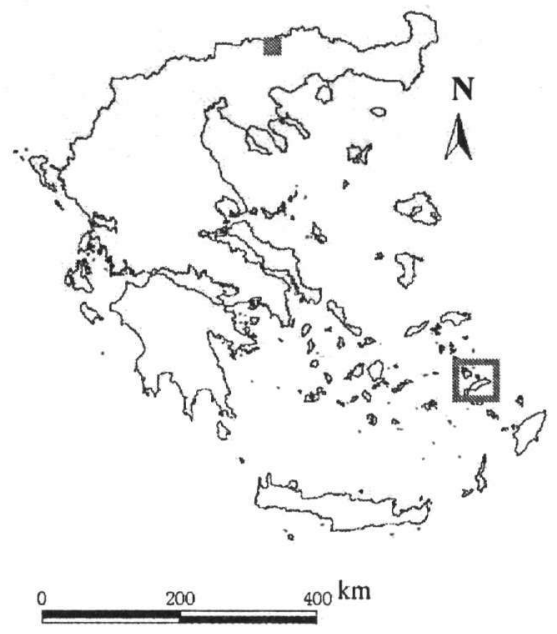

Fig. 1. Geographic position of Leucogia [ $\mathrm{W}]$ and Kos Island [ $\square]$ ].

\subsection{Kos island kaolins}

The kaolin occurrences of Kefalos, SW Kos Island, are products of hydrothermally altered rhyolitic rocks of Pliocene age (Boven et al. 1987). These rocks exhibit perlitic texture and are mainly composed of quartz, Na-plagioclase, K-feldspar and volcanic glass. The kaolin occurrences are white in color, commonly stained reddish by iron oxides, and extend over an area of about $0.5 \mathrm{~km}^{2}$. The highly altered samples contain dickite and kaolinite with an average total amount of about $60 \%$ (Papoulis 2003). Kaolin occurrences of Asfendiou area, NE Kos, are products of hydrothermal alteration of a $700 \mathrm{~m}$ long, $50 \mathrm{~m}$ wide rhyolitic dyke. Relics of unaltered rhyolite are rarely found. 


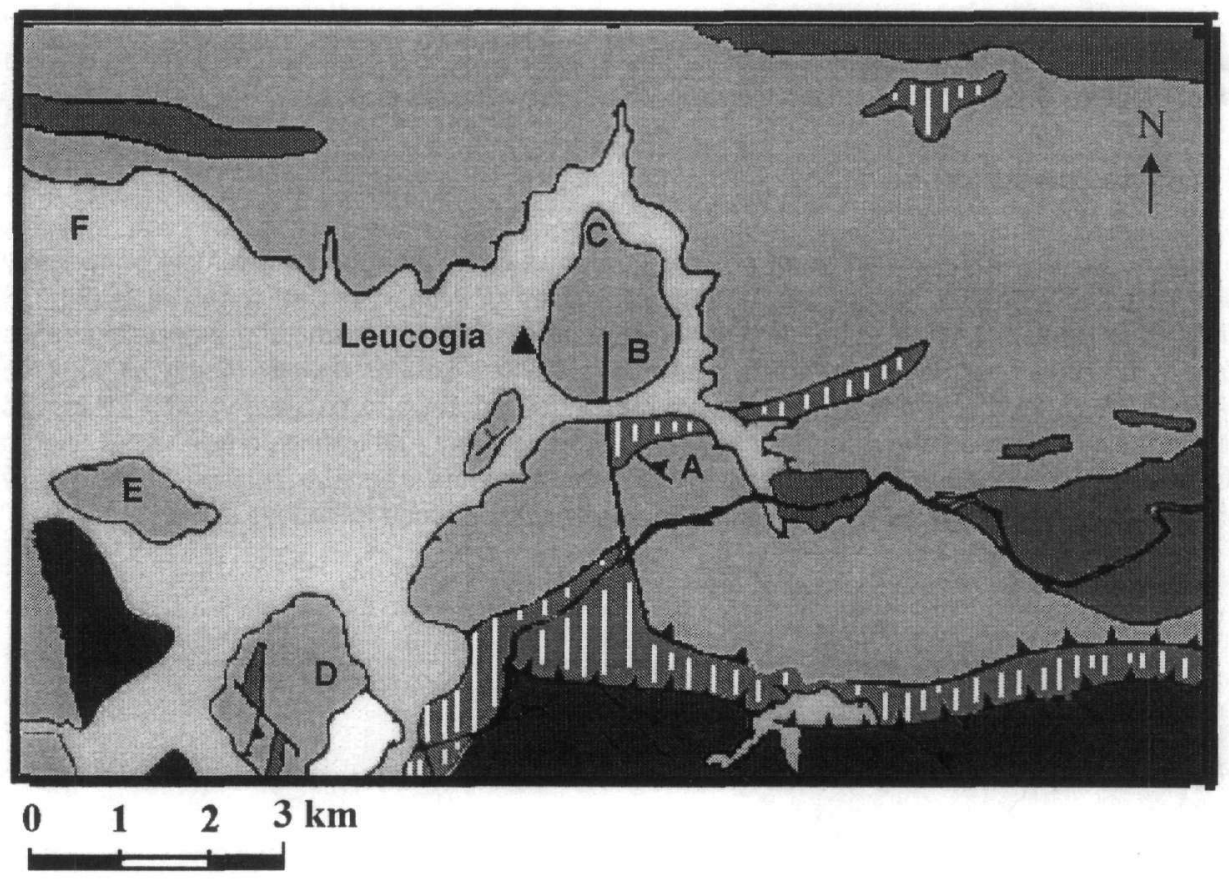

Fig. 2. Geological sketch map of Leucogia area (Chatzipanagis 1991).

A, B, C, D, E, F: Sample location

Marl Limestone

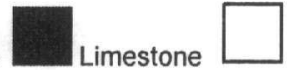

Gneisses

Leucocratic Muscovite Gneisses

Alternation of Schist, Gneisses and Marble

Alternation of Schist, Amphibolite and Gneisses

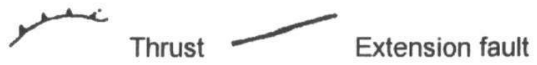

\section{MATERIALS AND METHODS}

\subsection{Materials}

Sixty samples were collected, across three vertical profiles, from fresh gneiss to the intensively kaolinized upper parts of the Leucogia area. The profiles are exposed in quarried deposits and the kaolin samples were collected after scraping the exposed surfaces.

Thirty samples from Kefalos and ten samples from the kaolinized rhyolitic dyke of Asfendiou Kos, were collected. 


\subsection{Methods}

Diagnostic evaluation of the quality of kaolins include particle size analysis, cation exchange capacity, brightness and whiteness and Atterberg limit tests.

The CEC of kaolin samples was determined using the ammonium acetate $\mathrm{NH}_{4} \mathrm{COOH}$ method described by Smith \& Mitchell (1987). Average values were calculated and recorded for each sample analyzed.

Atterberg limit tests conducted are the liquid limit (LL) and plastic limit (PL). The plasticity index (PI) was calculated based on the arithmetic difference of the LL and PL of the kaolins. The LL and PL tests were carried out with a Cassagrande apparatus.

The particle size distribution of the whole kaolin samples was measured using a gravity sedimentation technique with Andearsen pipette.

Brightness is defined as the ratio, expressed as a percentage, of the radiation reflected by a body to that reflected by a perfectly reflecting ISO (International Standards Organization)-approved $\mathrm{BaSO}_{4}$ Standard measured at an effective wavelength of $457 \mathrm{~nm}$ with a Care Zeiss photoelectric reflection photometer. Brightness is expressed as the difference between the percentage reflectance at $700 \mathrm{~nm}$ and $400 \mathrm{~nm}$. Whiteness is the colour as seen by the eye. This value was quantified by taking reflectance measurements at $400 \mathrm{~nm}$ and $700 \mathrm{~nm}$. Brightness and whiteness of the samples were determined by using a digital brightness meter (Color Tester LFM 1 Dr Lange type).

Kaolin texture and morphology of alteration minerals were examined at the Laboratory of Electron Microscopy and Microanalysis, University of Patras using a (JEOL 6300) Scanning Electron Microscope (SEM) equipped with EDS and WDS systems. The SEM images were obtained from gold-coated fracture surfaces of bulk kaolin samples mounted on stubs.

\section{RESULTS}

\subsection{Grain size distribution analysis}

Grain size distribution analyses of 4 representative samples of Leucogia kaolins and 3 representative samples of Kos kaolins are given in Table 1.

The kaolin grain size analysis shows that Leucogia and Kos kaolins are mostly finer than $75 \mu \mathrm{m}$ on average. The $<2 \mu \mathrm{m}$ fraction is on average $21 \%$ and $25 \%$ for the Leucogia and Kos kaolins respectively (Table 1). Thus Kos kaolins are relatively finer than Leucogia kaolins

\subsection{Atterberg limits}

Atterberg limit tests of 2 representative samples of Leucogia kaolins and 2 representative samples of Kos kaolins are given in Table 1.

Atterberg limit tests give an indication degree of plasticity from which an approximation of the kaolin viscosity and degree of crystallinity can be obtained. The LL, PL and PI values range between 20.53 and $35.22,11.48$ and 17.19 and 9.05 and 17.19 , respectively (Table 1).

\subsection{Scanning Electron Microscopy (SEM)}

Detailed SEM observations of samples from both areas revealed the morphology of kaolin minerals. Representative SEM micrographs of kaolin minerals from Leucogia and Kos island are given in Figs. 3-4.

In the Leucogia kaolin, halloysite and kaolinite exhibit different morphological forms and aggregations with the same rock sample (Fig 3a,b). In the Kos kaolin, book-type dickite forms after kaolinite and represents peak conditions of hydrothermal alteration. In this stage of kaolinization dickite forms tightly packed, unusually curved books (Fig $4 a, b$ ). These books show particularly dense packing so that a high magnification is necessary in order to distinguish dickite layers. 


\subsection{Cation Exchange Capacity (CEC)}

The CEC values of 3 representative samples of Leucogia kaolins and 3 representative samples of Kos kaolins are given in Table 1.

Remarkable differences in CEC values between the two kaolinitic clays studied have been observed. The CEC values of samples from Leucogia area range between $3.8 \mathrm{meq} / 100 \mathrm{~g}$ in the less altered, containing mostly spheres and tubes of halloysite, to $8 \mathrm{meq} / 100 \mathrm{~g}$ in the most altered samples (Table 1). In Kos, CEC values ranging between $2.2 \mathrm{meq} / 100 \mathrm{~g}$ in the less altered, kaolinite-rich sampes to $0.8 \mathrm{meq} / 100 \mathrm{~g}$ in the most altered, dickite-rich samples, have been determined (Table 1).

\subsection{Brightness and whiteness}

The brightness and whiteness of 6 representative samples of Leucogia kaolins and 4 representative samples of Kos kaolins are given in Table 1.

Compared to Kos, the Leucogia kaolin shows relatively higher brightness and whiteness. Brightness of the Leucogia kaolin samples is in the range of $47.3-60.2 \%$ and whiteness is in the range of $61.7-77.3 \%$. With the exception of the calcite-rich sample K47, brightness of the Kos kaolin samples is in the range of $40.7-48.3 \%$ and whiteness is in the range of $60.8-65.7 \%$. In Leucogia, the lowest values of brightness and whiteness were measured in sample L 44 characterized by the presence of platy halloysite.

\section{DISCUSSION}

Remarkable differences in CEC values between the two kaolinitic clays have been observed. The values obtained reflect the differences in clay mineralogy and the charactiristic kaolin mineral present (Figs. 3, 4). The presence of platy halloysite (Fig. 3a, b) in the most altered samples of Leucogia (Papoulis 2003; Papoulis et al. 2004) increases the CEC values of the Leucogia kaolins; kaolinite-rich samples from Kos exhibit higher CEC values than the most altered dickite-rich samples from the same area.

The LL, PL and PI values show that kaolin from both areas to be of medium plasticity. These properties are related to the CEC. According to the clay workability chart of Bain \& Highly (1978), the studied samples fall in the category of kaolinitic clays that are suitable for brick making (fig. 5).

Examined in terms of the ternary diagram silica-alumina-other oxides of Fabri and Fiori (1985), most of the kaolin samples plot into the white stoneware field (Fig. 6, from Papoulis et al. 2004). No sample from the studied areas, however, is close to the field of pure kaolins, which include most of the products from UK, France and Germany.

The Leucogia kaolin shows relatively higher brightness and whiteness than Kos kaolin. These properties are influenced by the type of kaolinite polymorph present, their relative proportions and the $\mathrm{Fe}_{2} \mathrm{O}_{3}$ content of the samples (Fig. 7). The presence of dickite coupled with a high $\mathrm{Fe}_{2} \mathrm{O}_{3}$ content reduces brightness and whiteness. In kaolinite-rich samples both brightness and whiteness show negative correlation with $\mathrm{Fe}_{2} \mathrm{O}_{3}$. However, in samples which are relatively rich in platy halloysite, brightness and whiteness are closely related to the $\mathrm{Fe}_{2} \mathrm{O}_{3}$ content. This relationship is attributed to the chemical composition of platy halloysite, which is Fe-rich and "traps" most of the $\mathrm{Fe}_{2} \mathrm{O}_{3}$ content of the kaolins, thus reducing iron impurities. The obtained values of brightness and whiteness for samples of both areas are lower compared to the standard commercial kaolins for the paper and filler market. Brightness, however, can be improved by fine grinding and refinement. 

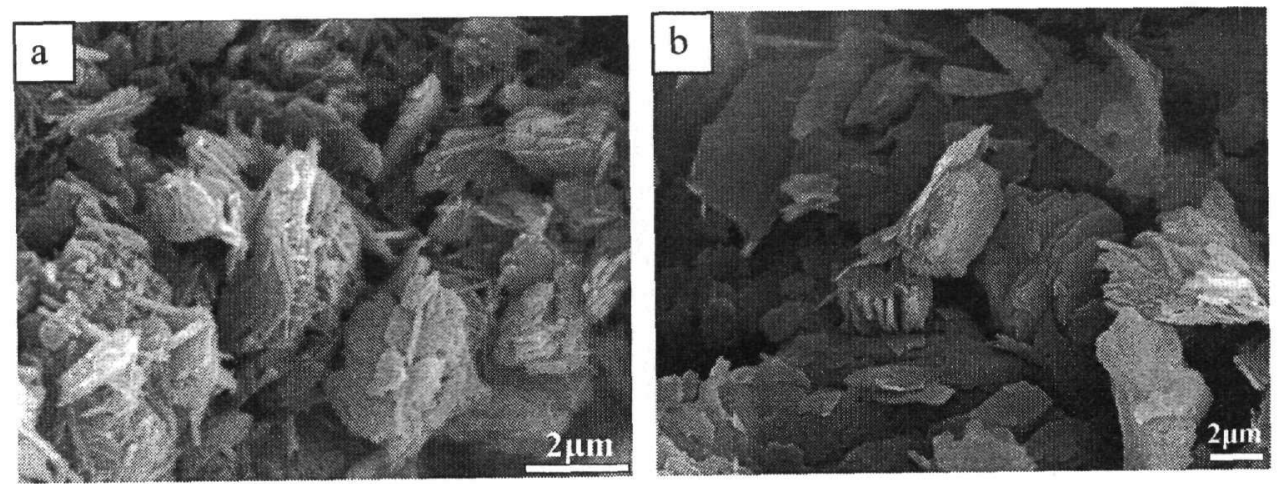

Fig. 3. SEM microphotographs showing tubular halloysite and interconnected tubes of halloysite forming felted planar masses of halloysite and poorly developed platy halloysite and kaolinite from Leucogia (a) and not well formed kaolinite books from Leucogia (b).
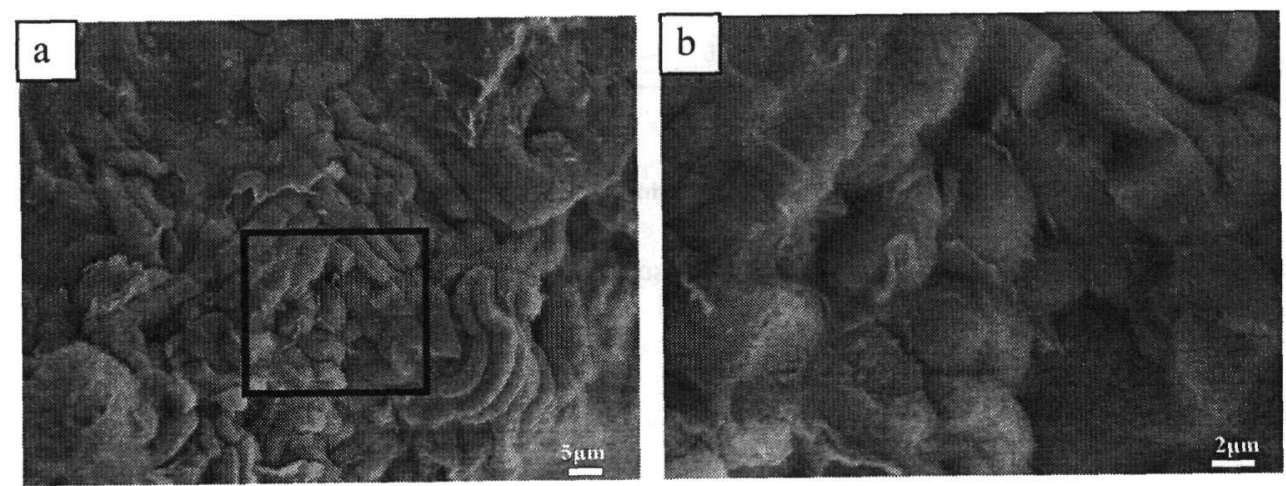

Fig. 4. SEM microphotographs showing curved, tightly - packed books of dickite (a) and magnification of the box in Fig. 4a from Kos island (b).

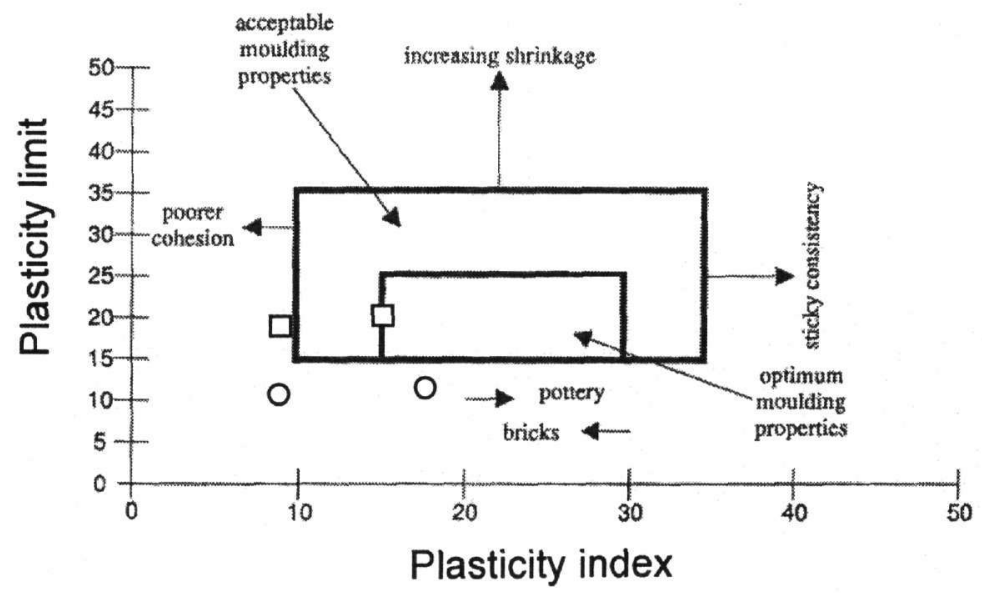

Fig. 5. Representative kaolin samples plotted on the clay workability chart of Bain \& Highly (1978). : Samples from Leucogia, $\square$ : Samples from Kos. 


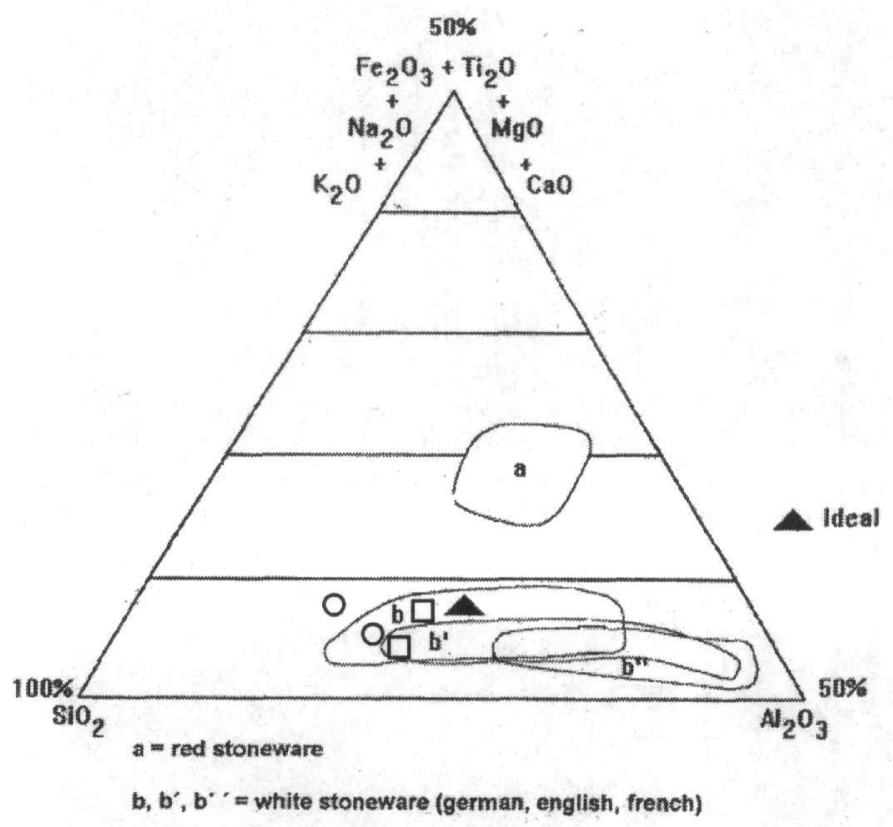

Fig. 6. Representative samples of Leucogia ( Qand Kos kaolins ( ) mina - other oxides of Fabri \& Fiori (1985).
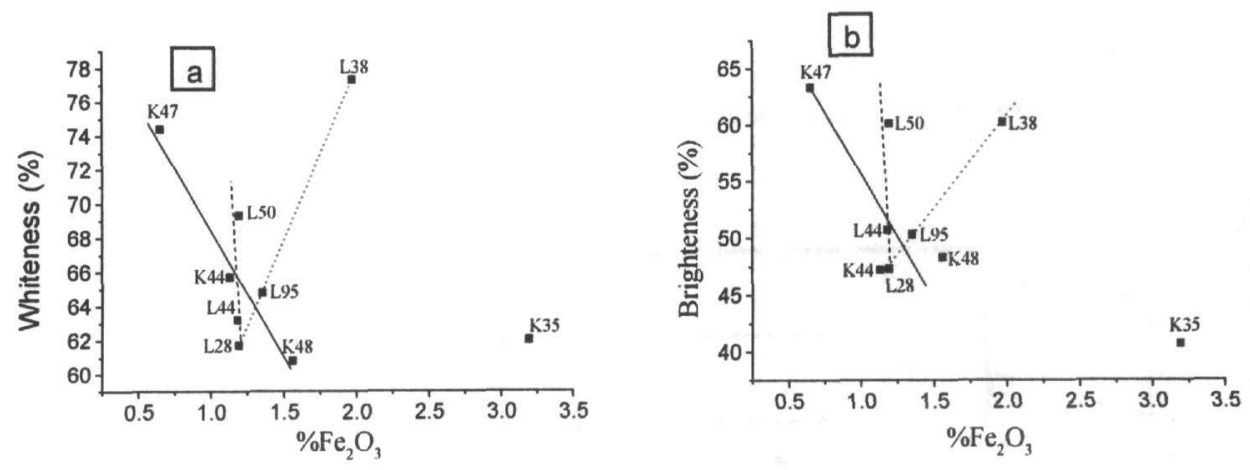

Fig. 7. Correlations between whiteness and $\% \mathrm{Fe}_{2} \mathrm{O}_{3}(\mathrm{a})$ and brightness and $\% \mathrm{Fe}_{2} \mathrm{O}_{3}(\mathrm{~b})$.

Dot lines connect platy halloysite rich samples from Leucogia.

Dash lines connect kaolinite rich samples from Leucogia

Black lines connect kaolinite rich samples from Kos

$\mathrm{K} 35$ : dickite rich sample from Kos 


\begin{tabular}{|c|c|c|c|c|c|c|c|c|c|}
\hline \multirow[b]{2}{*}{ Locality } & \multirow[b]{2}{*}{$\begin{array}{l}\text { Sample } \\
\text { no }\end{array}$} & \multicolumn{4}{|c|}{ PHYSICAL PROPERTIES } & \multicolumn{4}{|c|}{ CERAMIC PROPERTIES } \\
\hline & & $\begin{array}{l}\text { Grain - } \\
\text { size } \\
\%<2 \mu \mathrm{m}\end{array}$ & $\begin{array}{l}\text { Analysis } \\
\%<75 \mu \mathrm{m}\end{array}$ & Brightness & Whiteness & CEC & LL & PL & PI \\
\hline \multirow[t]{8}{*}{ Leucogia } & L28 & 11 & 89 & 50.7 & 63.2 & 3.8 & & & \\
\hline & L34 & 23 & 77 & & & & & & \\
\hline & L44 & 33 & 67 & 47.3 & 61.7 & 8.0 & 20.53 & 11.48 & 9.05 \\
\hline & L50 & 16 & 84 & 60.1 & 69.3 & & & & \\
\hline & L38 & & & 60.2 & 77.3 & 7.0 & & & \\
\hline & L51 & & & 52.1 & 64.3 & & & & \\
\hline & L95 & & & 50.3 & 64.8 & & 28.70 & 11.51 & 17.19 \\
\hline & & $\begin{array}{l}\text { Mean } \\
21 \\
\end{array}$ & $\begin{array}{l}\text { Mean } \\
79 \\
\end{array}$ & & & & & & \\
\hline \multirow[t]{7}{*}{ Kos } & K35 & 36 & 64 & 40.7 & 62.0 & 0.8 & 28.61 & 19.09 & 9.52 \\
\hline & K46 & 11 & 89 & & & & & & \\
\hline & K48 & 27 & 73 & 48.3 & 60.8 & 1.4 & 35.22 & 15.08 & 15.08 \\
\hline & K44 & & & 47.2 & 65.7 & & & & \\
\hline & K47 & & & 63.3 & 74.4 & & & & \\
\hline & K9 & & & & & 2.2 & & & \\
\hline & & $\begin{array}{l}\text { Mean } \\
25\end{array}$ & $\begin{array}{l}\text { Mean } \\
75\end{array}$ & & & & & & \\
\hline
\end{tabular}

\section{CONCLUSIONS}

The physical, chemical and mineralogical properties of Leucogia and Kos kaolins indicate that they are of low grade type. However, kaolin processing from the crude state can optimize some of these highly commercial properties.

The presence of platy halloysite in Leucogia kaolins "traps" most of the $\mathrm{Fe}_{2} \mathrm{O}_{3}$ content of the kaolins, reducing iron impurities and increases their CEC values, improving thus the kaolin quality significantly.

In the most altered samples of Kos dickite forms tightly packed, unusually curved books. The above morphology results in a decrease of the surface area along with CEC. The presence of dickite in Kos kaolins coupled with a high $\mathrm{Fe}_{2} \mathrm{O}_{3}$ content reduces brightness, whiteness and kaolin quality.

\section{REFERENCES}

Bain J.A. \& Highly D.E. 1978. Regional appraisal of clay resources challenge to the clay mineralogist. In: Mortland M.M. \& Farmer V.C. (eds), Proc. Int. Clay Conference, Elsevier, Amsterdam, 437-446.

Boven A., Brousse R., Dalabakis P. \& Pasteels P. 1987. Geological and geo-chronological evidence on the evolution of Kos-Yali-Nisyros eruptive centers, Aegean arc, Greece. Terra Cognita, 328-329.

Chatzipanagis I. 1991. Geological structure of the broader area of Falakro mountain. Ph.D Thesis, Technical Univ. Athens, 170p.

Fabbri B. \& Fiori C. 1985. Clays and complementary raw materials for stoneware tiles. Mineralogica et Petrographica Acta, 535-545.

Michailidis K. \& Tsirambides A. 1986. The Kaolin deposits of Leucogia, NE Greece. Clay Minerals, 21, 417-426, (Note).

Murray H.H. 1991. Overview - Clay Mineral Applications. Appl. Clay Sci., 5, 379-395. 
Murray H.H. \& Keller W.D. 1993. Kaolins, kaolins and kaolins In: Murray H.H., Bundy, W.M. \& Harvey, C.C., (eds), Kaolin Genesis and Utilization, The Clay Minerals Society, Boulder, CO.

Papoulis D., Tsolis-Katagas P. \& Katagas C. 2004. Progressive stages in the formation of kaolinite from halloysite in the weathering of plagioclase. Clays and Clay Minerals, 52, 3, 275-286.

Papoulis D. 2003. Mineralogical study, kaolinitization processes and properties of kaolins from Leucogia Drama and Kos Island. Ph. D Thesis, Univ. Patras, 289p.

Smith B.F.L. \& Mitchell B.D. 1987. Characterization of poorly ordered minerals by selective chemical methods. In: Wilson, M.J., (ed.) A handbook of determinative methods in Clay Mineralogy, 308p. 